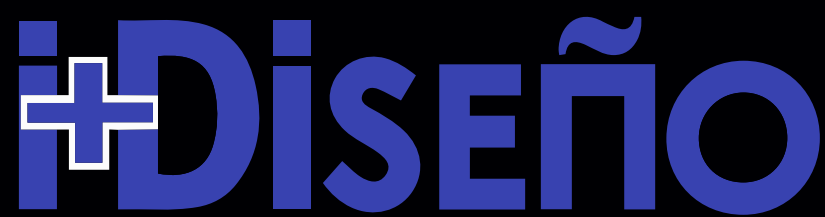

Revista científico-académica internacional de Innovación, Investigación y Desarrollo en Diseño - ISSN 1889-433X

\title{
Entrevistas a: \\ Felipe Formariz y Soledat Berbegal
}

Juan Aguilar, Javier Fernández y Sebastián García Garrido

\section{Entrevista a Felipe Formariz Pombo}

Subdirector General de Coordinación y Relaciones Institucionales del Ministerio de Ciencia, Innovación y Universidades. Administrador Civil del Estado. Ha sido Subdirector General de Marketing Exterior del Turismo (Turespaña), Director de la Oficina Española de Turismo en Bruselas, y Vocal Asesor de la D.G. de Comunicación e Información Diplomática el Ministerio de Asuntos Exteriores y Cooperación, entre otros puestos de relevancia.

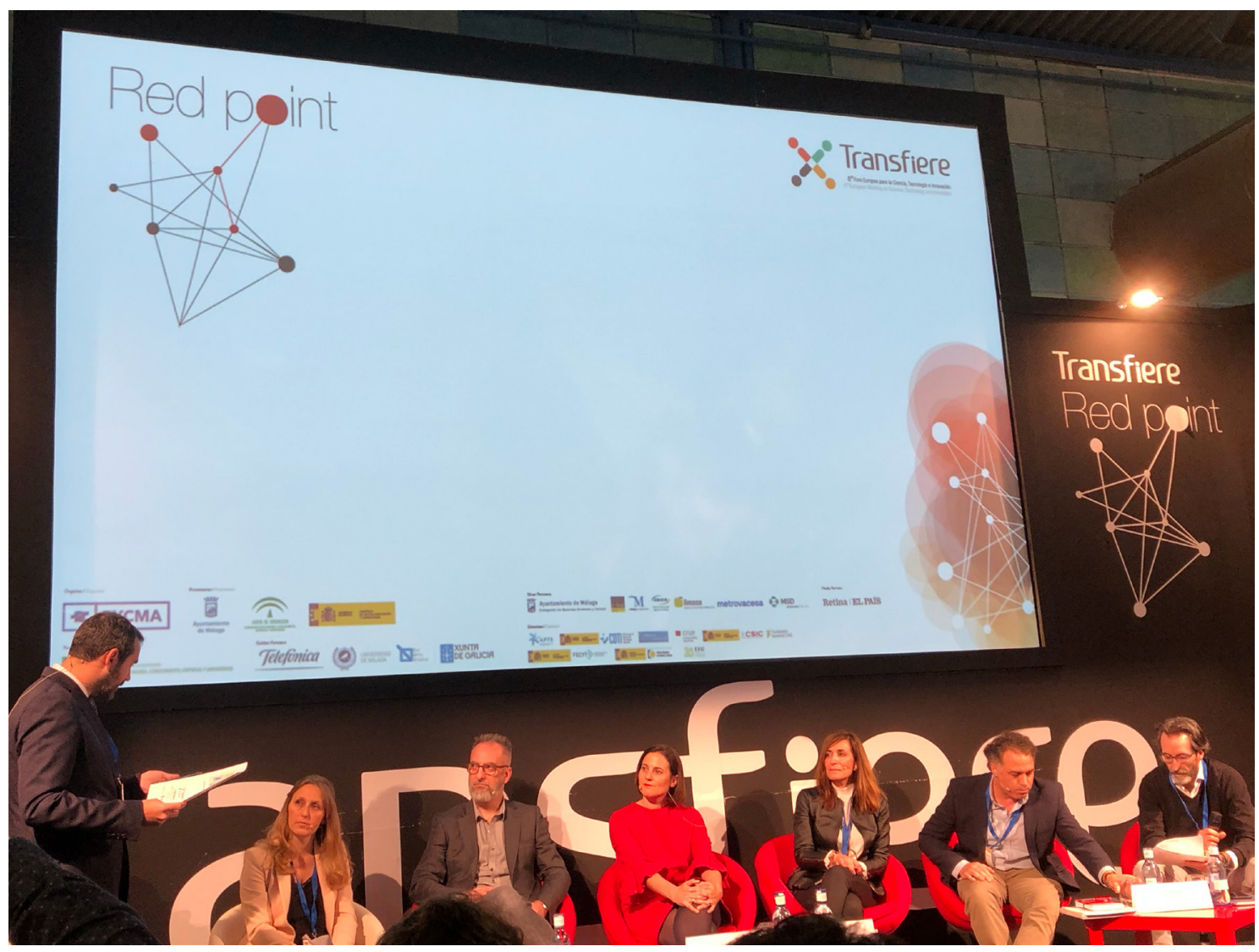

Fig.1. Mesa sobre Diseño en el Foro Transfiere. Málaga, febrero 2019. Interviene Felipe Formariz y participa Soledat Berbegal. 


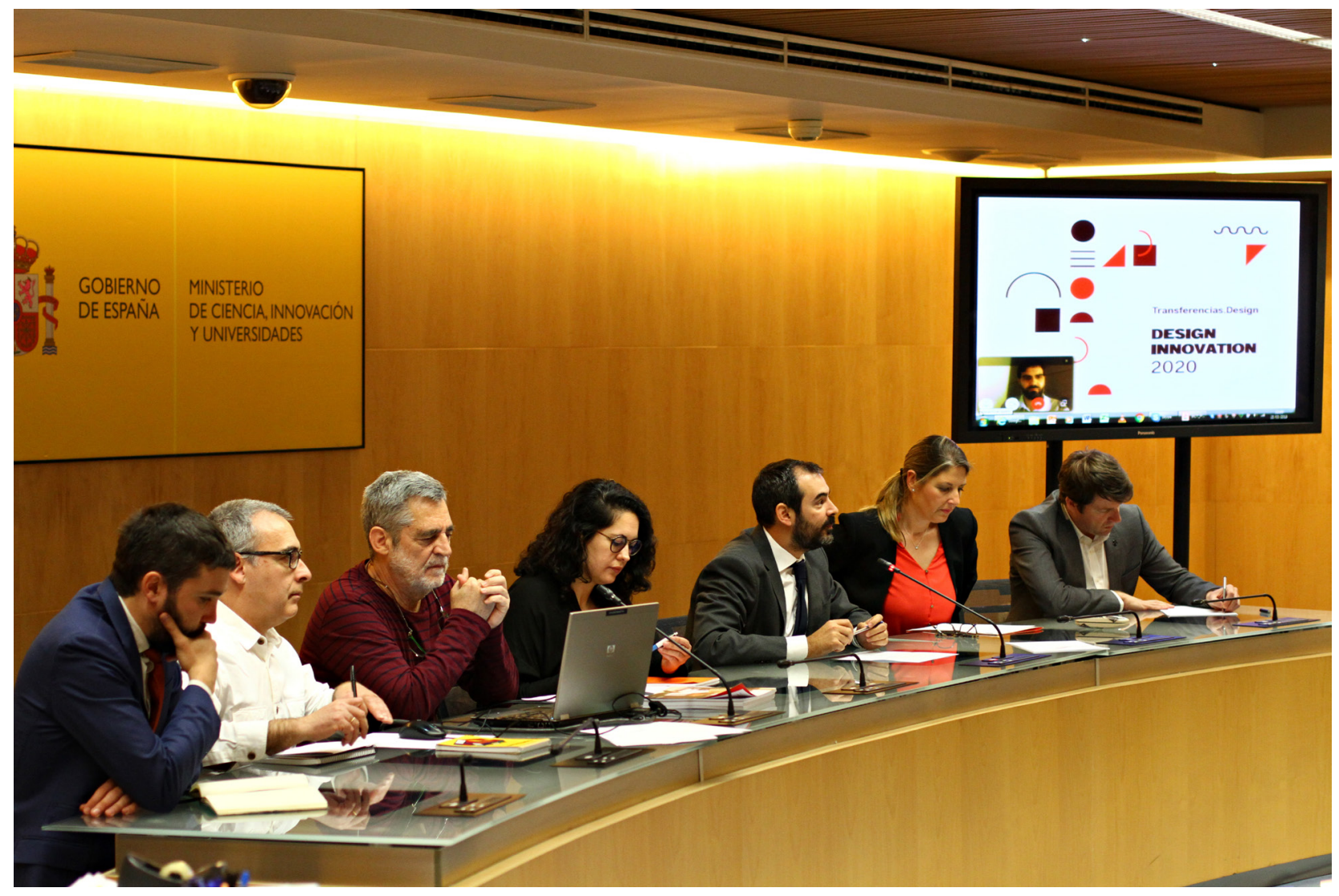

Fig.2. Felipe Formariz. Mesa de reunión de Transferencias Design. Ministerio de Ciencia, Innovación y Universidades. Madrid, marzo 2019

\section{- ¿Por tu experiencia en la promoción exterior del turismo, cómo es la imagen de España fuera de nuestras fronteras y cómo podría mejorarse?}

Se trata de una cuestión bastante compleja, sobre todo si partimos de que la marca país está integrada por diferentes dimensiones. Cada una de estas dimensiones tiene un peso mayor o menor en cada país, lo que afecta a su vez a la percepción que se tiene sobre España. De este modo encontramos países en los que la imagen de España es muy completa y positiva, y otros países en los que España apenas es conocida. En general me atrevería a decir que en los países que son más estratégicos para España la situación es la primera.

En cualquier caso, como señalaba antes, la marca país está integrada por diferentes dimensiones. Si tomamos el modelo de identidad competitiva de Simon Anholt las categorías son seis. Pero si tomamos algunos modelos más complejos de consultoras de marca las variables se multiplican. En cada una de estas dimensiones el público objetivo es distinto: no es lo mismo a quien nos dirigimos en turismo, que en exportaciones o captación de inversiones. Todo ello hace que sea aún más difícil de manejar la imagen y la reputación de un país. 
- ¿Con la experiencia en la Oficina Española de Turismo en Bruselas qué constancia tienes de la necesidad de promover el desarrollo del diseño estratégico en el sector turístico por parte de las instituciones o de las empresas?

El diseño estratégico debería ser un elemento clave a la hora de definir las estrategias de las empresas y de las políticas públicas en cualquier sector. Sin embargo es algo sobre lo que aún tenemos que seguir trabajando ya que apenas está implantado. De acuerdo con el Innobarómetro de 2015 sólo el 12\% de las empresas españolas consideraban el diseño como una estrategia. Aunque esta cifra se haya podido incrementar, las cifras serán aún bajas. Con relación al turismo, creo que no hay disponibles datos sectoriales. Sí puedo decir, sin embargo, que es un sector dinámico e innovador donde el diseño juega un papel importante en muchas empresas.

En cualquier caso, aún queda bastante camino por recorrer y aquí empresas y administraciones públicas deben ir de la mano.

- ¿Por la experiencia profesional fuera de España, crees que el diseño es un factor decisivo en el aumento del PIB? ¿Si nuestro país tiene un potencial destacado en Diseño y si hay alguna acción o promoción en manos del Estado para desarrollar una mayor implicación del Diseño en las empresas y en los proyectos institucionales?

Está claro que el diseño, como elemento clave en el proceso de innovación, juega un papel económico relevante y, por tanto, contribuye al aumento del PIB. La dificultad está, actualmente, en poder cuantificar exactamente cuál es esa contribución ya que el diseño tiene un carácter transversal y líquido.

España es un país que tiene un importante potencial en el ámbito del diseño, y no me refiero solamente a los subsectores que son más conocidos, como el diseño gráfico, el diseño de muebles e interiores o el diseño industrial. También lo es en otros ámbitos menos conocidos como el diseño de procesos o la consultoría de diseño estratégico.

La Administración General del Estado cuenta con herramientas de promoción exterior de gran parte de esos sectores. Es principalmente el ICEX quien es responsable de esa promoción fuera de nuestro país. Las Cámaras de Comercio, en coordinación con ICEX, también juegan un papel muy importante. Y el resto de ámbitos sectoriales que están presentes en el exterior, también utilizan el diseño, siempre que es posible, como elemento de reclamo y venta de España en el mundo.

En cualquier caso, para obtener el éxito, es clave conocer bien los mercados y las necesidades de los consumidores. En la nueva economía, si algo no tiene un buen diseño (y aquí hay que combinar los elementos funcional y los estéticos) no despega. Debemos ajustarnos a cómo es la gente, a sus gustos y a sus necesidades para ser capaz de ofrecer algo que les interese. Hay que personalizar los productos y servicios. Por ello el diseño basado en la experiencia de usuario es un factor de éxito.

Estoy de acuerdo con vosotros en que el diseño requiere un vínculo permanente entre el diseñador, los macro/microdatos y la retroalimentación de la experiencia de usuario. Pero también hay que dejar campo a la experimentación de escenarios futuros y la detección de tendencias de los nuevos usuarios. Algunas empresas e instituciones promueven becas, estancias e incluso ofertas de trabajo para jóvenes que permiten la incorporación de esta nueva visión más fresca para la empresa. 
- ¿Qué opinas del papel del diseño alrededor de la generación de ecosistemas productivos locales?

La ciudad está jugando un papel muy importante en el desarrollo de ecosistemas vinculados al diseño.

En España existen numerosas iniciativas que quieren consolidar a las ciudades españolas como polos del diseño.

Barcelona es sin duda la ciudad pionera en este sentido, pero le han salido bastantes competidoras: Bilbao, Málaga, Madrid o Valencia son buenos ejemplos de ello (y esto seguro que me estoy dejando algunas), con actividades a lo largo del año de gran calidad.

Lo positivo de todas estas iniciativas es que tienen un posicionamiento propio y reflejan las idiosincrasias locales. No es una mera repetición y copia de actividades sin coherencia alguna. Y esto es bueno porque el diseño se configura como un elemento diferenciador en el posicionamiento de estas ciudades y consigue resultados.

- Frente a la contundencia de la tecnología hoy y el gran poder de atracción de los ingenieros y su innovación tecnológica, Jorge Paricio, profesor en la Rhode Island School of Design, ha recopilado en un interesante artículo en este número, una serie de referentes de la mayor relevancia internacional sobre la necesidad de complementar la formación preuniversitaria, en ciencias y sobre todo en ingeniería, con un complemento de asignaturas vinculadas al arte y el diseño para que desarrollen una mayor capacidad creativa ¿Cómo ves tú esta cuestión algo alejada de tu área de trabajo?

El diseño, a mi modo de ver, tiene dos componentes que son importantes: el funcional y el estético. Podemos tener un producto con una gran funcionalidad que, si no tiene una estética adecuada (aunque sea sencilla), es posible que no triunfe en el mercado; y al contrario, podemos encontrar un producto que estéticamente pueda ser muy atractivo pero que al final solo tenga un componente decorativo porque no podemos utilizarlo y termine en un rincón.

Por lo tanto creo que es bueno incorporar, tal vez no el conocimiento, pero sí la sensibilidad hacia el otro ámbito del conocimiento. De este modo será posible valorar mejor el trabajo de unos y de otros y los resultados serán mejores. Hoy en día la tendencia es a crear equipos multidisciplinares, y estos sólo funcionan si sus integrantes son capaces de abrir su mente hacia las aportaciones de los demás.

- Desde tu nombramiento has tenido una relación bastante intensa con el sector del diseño español a pesar del poco tiempo que llevas en el cargo (reuniones en el MCIU, eventos como Transferencias. Design o Foro Transfiere, entrevista en Grafica, intervención en Madrid Design Festival, etc.) ¿cómo nos ves? ¿Cuál es tu impresión?

Es cierto que llevo poco tiempo en este puesto, pero mi vínculo con el diseño viene desde muy atrás. Afortunadamente he tenido la oportunidad de trabajar con profesionales del diseño (gráfico, de procesos, estratégico, etc.) en puestos anteriores, en la puesta en marcha de actuaciones en políticas que no son la política de diseño, de modo que puedo decir que he sido "cliente" de los diseñadores, lo cual me complementa con la visión actual. Creo que es un sector muy profesional y con mucho potencial. Lo que falta es que la sociedad se convenza de la importancia del diseño en la mejora de sus vidas, y ahí es donde el sector tiene que seguir trabajando de forma importante. Otros sectores lo están haciendo, y por tanto es un reto que es posible conseguir. 


\section{Entrevista Soledat Berbegal}

Soledat Berbegal es Consejera y Directora de Reputación de Marca en Actiu, empresa familiar y Premio Nacional de Diseño 2017, especializada en el diseño y fabricación de muebles para espacios de trabajo y contract presente en más de 90 países. Su trabajo está ligado a la proyección internacional de la marca Actiu a través de proyectos comprometidos con la investigación, sostenibilidad, diseño o tecnología, centrando su esfuerzo en fomentar relaciones corporativas estratégicas y consolidar la percepción del mobiliario como una herramienta para mejorar el bienestar y la productividad en espacios de trabajo.

Ese compromiso por la innovación, por la calidad y también por el medio ambiente de Actiu se refleja en su Parque Tecnológico, certificado Leed Platino, y le ha valido en 2017 a su fundador, Vicente Berbegal, el premio al Empresario Europeo del Año de los European Business Awards, el certamen empresarial más exigente de Europa.

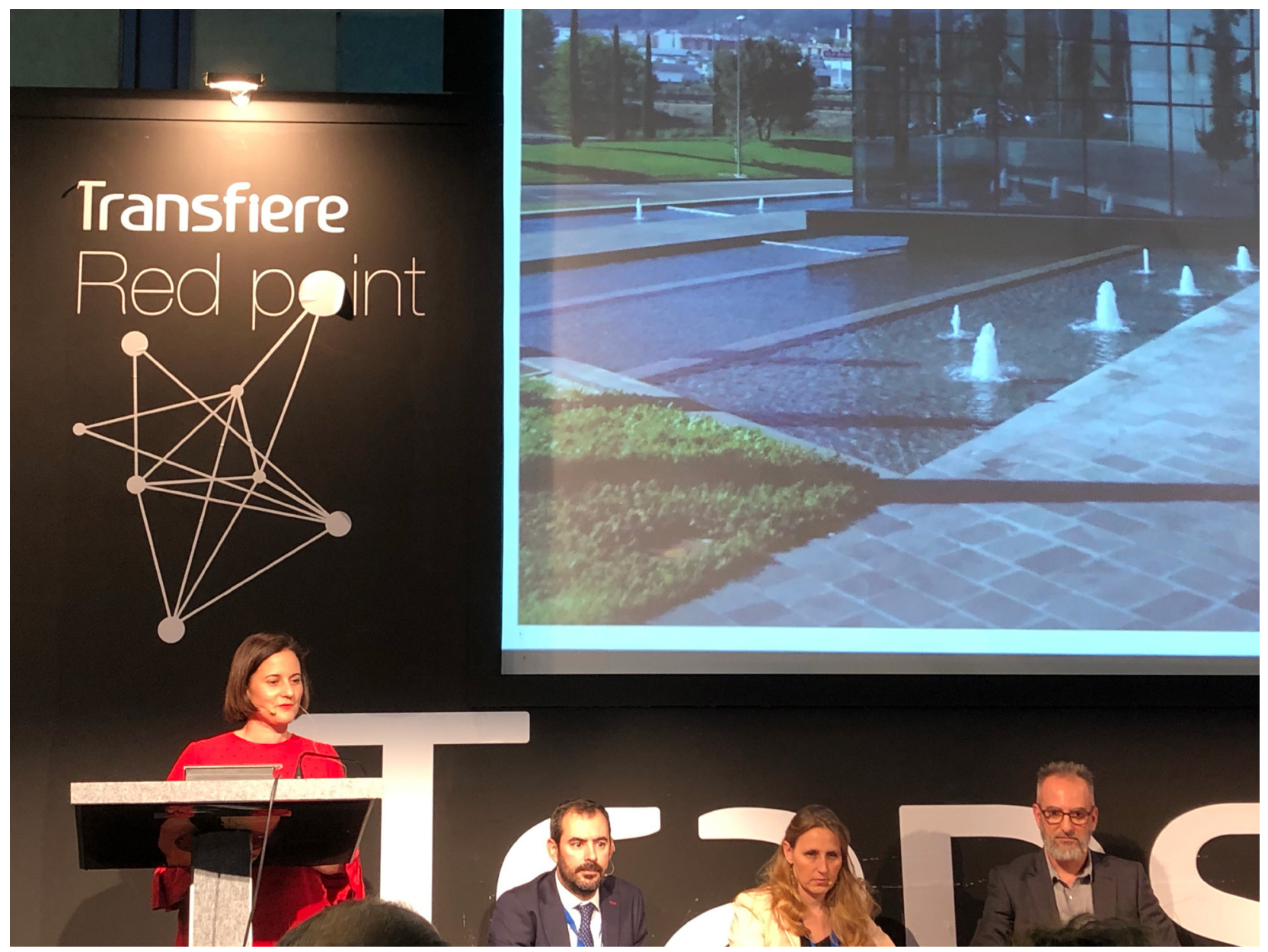

Fig.3. Intervención de Soledat Berbegal en Foro Transfiere. Málaga, febrero 2019. 


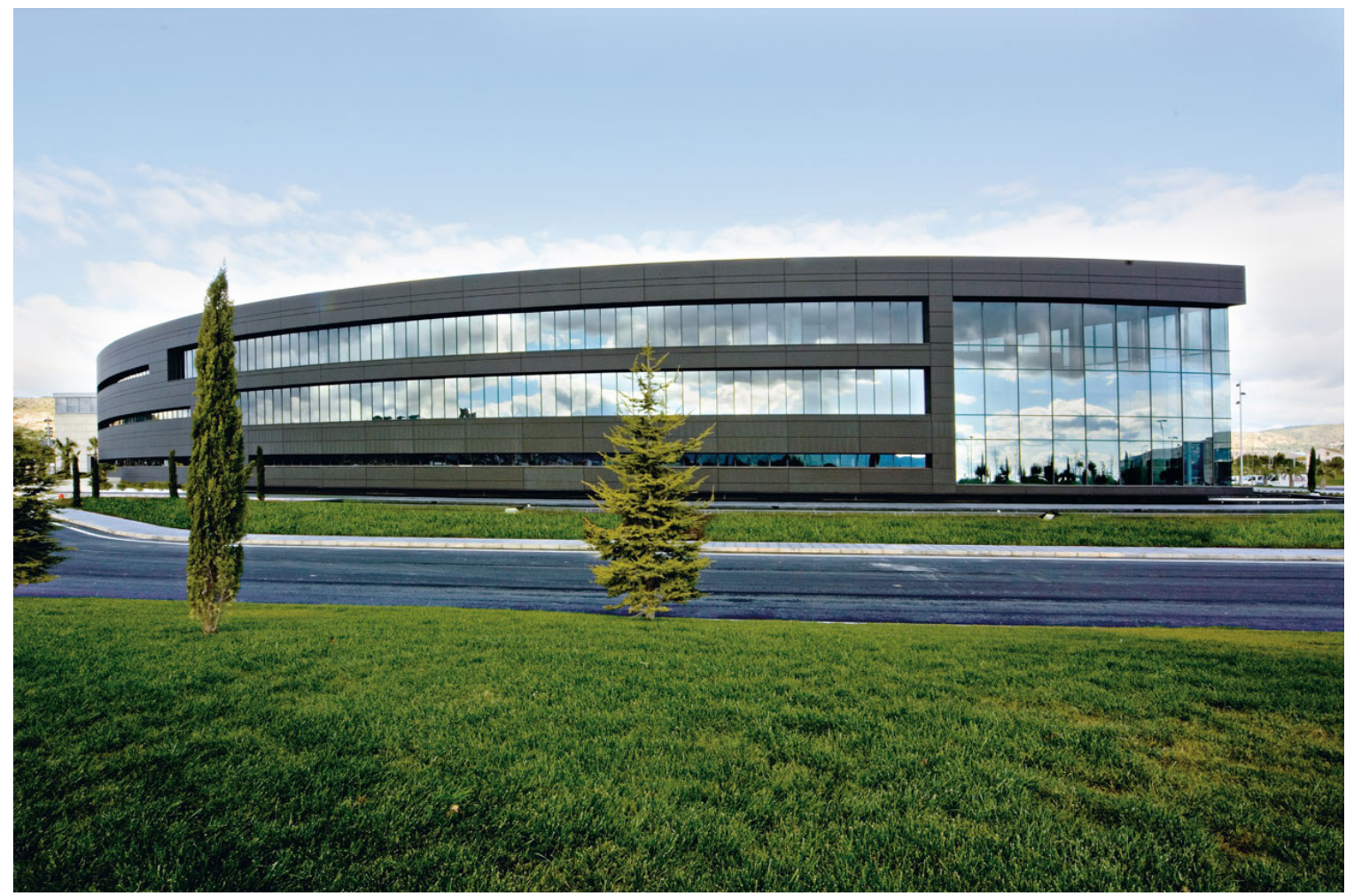

Fig. 4. www.actiu.com

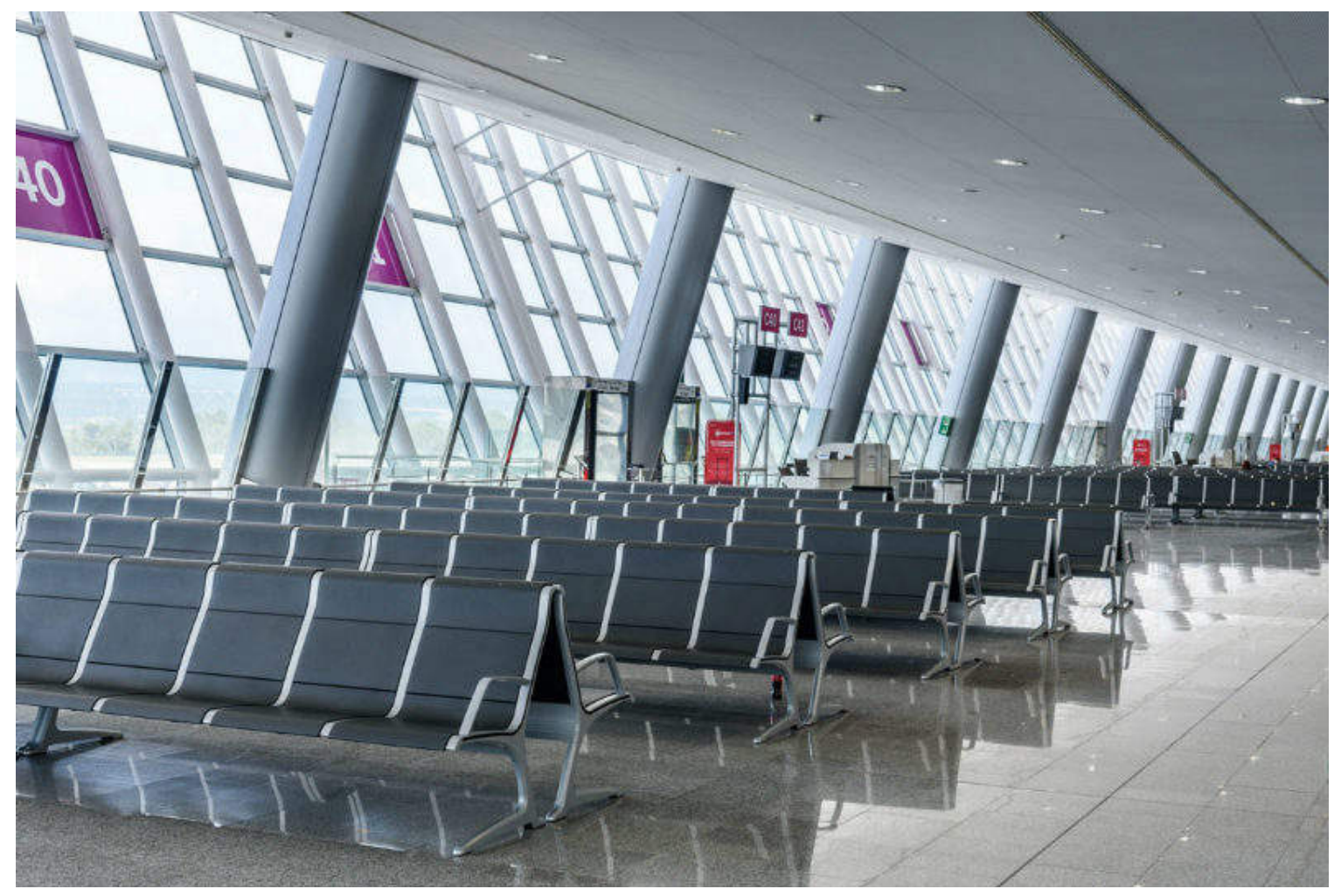

Fig. 5. www.actiu.com 
- ¿Por tu experiencia internacional con otras empresas, cómo es la imagen de la Marca España fuera de nuestras fronteras y cómo podría mejorarse?

En el ámbito del diseño de mobiliario la marca España es muy potente. Está muy bien considerada gracias al impulso de muchas empresas españolas que han apostado por el diseño, la fabricación propia y la calidad para ofrecer productos de mucho nivel y muy competitivos en precio. Sin embargo, aún no tenemos el reconocimiento de otros países como Italia o los nórdicos. Necesitamos hacer equipo para mostrar al mundo nuestras cualidades como fabricantes, así como un mayor apoyo e impulso de las instituciones que muestren el diseño como el único camino.

- Desde una de las regiones por excelencia del turismo español, como es el Levante ¿Qué constancia tienes de la necesidad de promover el desarrollo del diseño estratégico en el sector turístico por parte de las instituciones o de las empresas?

Es clave. Necesitamos una estrategia a largo plazo que nos relacione no sólo con el turismo sino con muchos otros ámbitos como pueda ser la cultura, la tradición, la gastronomía, la empresa, la sanidad... En eso, el diseño tiene mucho que decir: desde los conceptos a poner en valor, los destinos, la comunicación gráfica en la que apoyarse o incluso, los recuerdos, etc. Necesitamos un pensamiento estratégico que sea capaz de generar una experiencia memorable en quienes nos visitan gracias a una oferta turística que combina trabajo y ocio, espectáculos y congresos, deporte y cultura, territorio, salud y diseño... Todas aquellas cuestiones que pueda requerir un turista, independientemente de si viene a veranear, a practicar bici en la montaña o a trabajar.

- ¿Crees que el diseño es un factor decisivo en el aumento del PIB español? ¿Crees que nuestro país tiene un potencial destacado en diseño? ¿Crees que el Estado tiene en sus manos alguna acción o promoción para desarrollar una mayor implicación del diseño en las empresas y en los proyectos institucionales?

El diseño conecta con las emociones y contribuye a crear una experiencia increíble e inigualable en cuanto al equilibrio de precio, calidad y garantía. El diseño permite transmitir creatividad, innovación y un carácter propio.

Recientemente se ha hecho público un estudio, realizado por la Asociación de Diseñadores de la Comunitat Valenciana (ADCV), que afirma que el diseño es rentable, que tiene un impacto económico sin precedentes en el territorio donde se aplica y que genera un valor añadido y una diferenciación en todas aquellas empresas que lo ponen en práctica. Aunque los datos que recoge este informe son locales, sí son exportables a otros territorios. Tanto es así que, según indica este estudio, "el $70 \%$ de las industrias con una fuerte vinculación con el diseño son también aquéllas con una mayor expectativa de crecimiento".

- ¿Qué opinas del papel del diseño alrededor de la generación de ecosistemas productivos locales?

Es fundamental. En nuestro caso ya ocurrió en los años 80 con la crisis del juguete en la región y la implantación del plástico en nuestros muebles. Gracias a la colaboración de diseñadores externos, y la introducción de la inyección de plástico en nuestros muebles, conseguimos reorientar a muchas empresas auxiliares que tenían un gran bagaje industrial hacia nuestro sector. Así, mediante una estrategia empresarial de diseño, que engloba procesos, materiales y edificios, generamos una herramienta que permitió hacer competitivo este territorio. 
Al rediseñar procesos mejoramos costes, al rediseñar los productos fuimos más eficientes en la fabricación $y$, al rediseñar nuestras instalaciones aplicando principios de sostenibilidad, consumimos menos recursos naturales.

Con diseño y una visión que mire al futuro, se puede crear riqueza y trabajo en nuestro entorno gracias a la diferenciación y a un pensamiento estratégico.

\section{- ¿Cómo ves tú esta cuestión algo alejada de tu área de trabajo?}

Yo he aprendido estos años que el diseño nos hace la vida más sencilla, y además, más creativa. La mezcla de arte, creatividad, funcionalidad y practicidad que lleva detrás un buen diseño es sin duda un plus adicional a cualquier pensamiento lógico. Creo que es muy importante reflexionar sobre cómo hacemos las cosas, cómo las contamos, cómo las acabamos o cómo las presentamos. Y en eso el diseño tiene mucho que decir, y puede hacer que todo sea más práctico, más bonito, más eficiente y más diferente.

- ¿Sabías que el Diseño no es una disciplina autónoma como área de conocimiento y crees posible que el Diseño lo sea al margen del Dibujo o de otras áreas propias de la Arquitectura o la Ingeniería?

El diseño es multidisciplinar y debe impregnar estudios, funciones, departamentos y empresas. Necesitamos diseñadores en las áreas de finanzas, producción, ventas y tecnología de la información, entre otros. Personas cuya visión se expande más allá de la linealidad y del presente y que consiguen crear procesos nuevos, capaces de arrojar resultados diferentes y mejores.

\section{- ¿Cómo ves el momento del ecosistema del diseño y sus relaciones con las administraciones?}

El diseño es sinónimo de planificación, diferenciación, rentabilidad y competitividad. Es una filosofía de vida y un generador de imagen de marca. Y pone en valor, a través de los sentidos, los valores de una organización. Sin diseño no somos nada y si las empresas apostamos por el diseño como inversión, las administraciones públicas seguirán este camino, más pronto que tarde.

Rediseñar pensando en el cliente, o en el ciudadano, permite conectar mejor la esfera con la personal. Así, por ejemplo, desde su casa y gracias a una buena campaña de comunicación oficial, el usuario puede enterarse de avances y proyectos e incluso aportar sus opiniones. El diseño de la comunicación abre un horizonte importante que la Administración debería abordar. Estar cerca del usuario y de la sociedad en general supone prosperar y evolucionar a nivel cultural, educativo y social. En la educación primaria, los niños ya deberían estar aprendiendo sobre la importancia del papel que tiene el diseño en nuestras vidas. El buen diseño es aquél que les va a mejorar su día a día porque un buen diseño, por encima de la estética y la funcionalidad, está al servicio de las personas. 


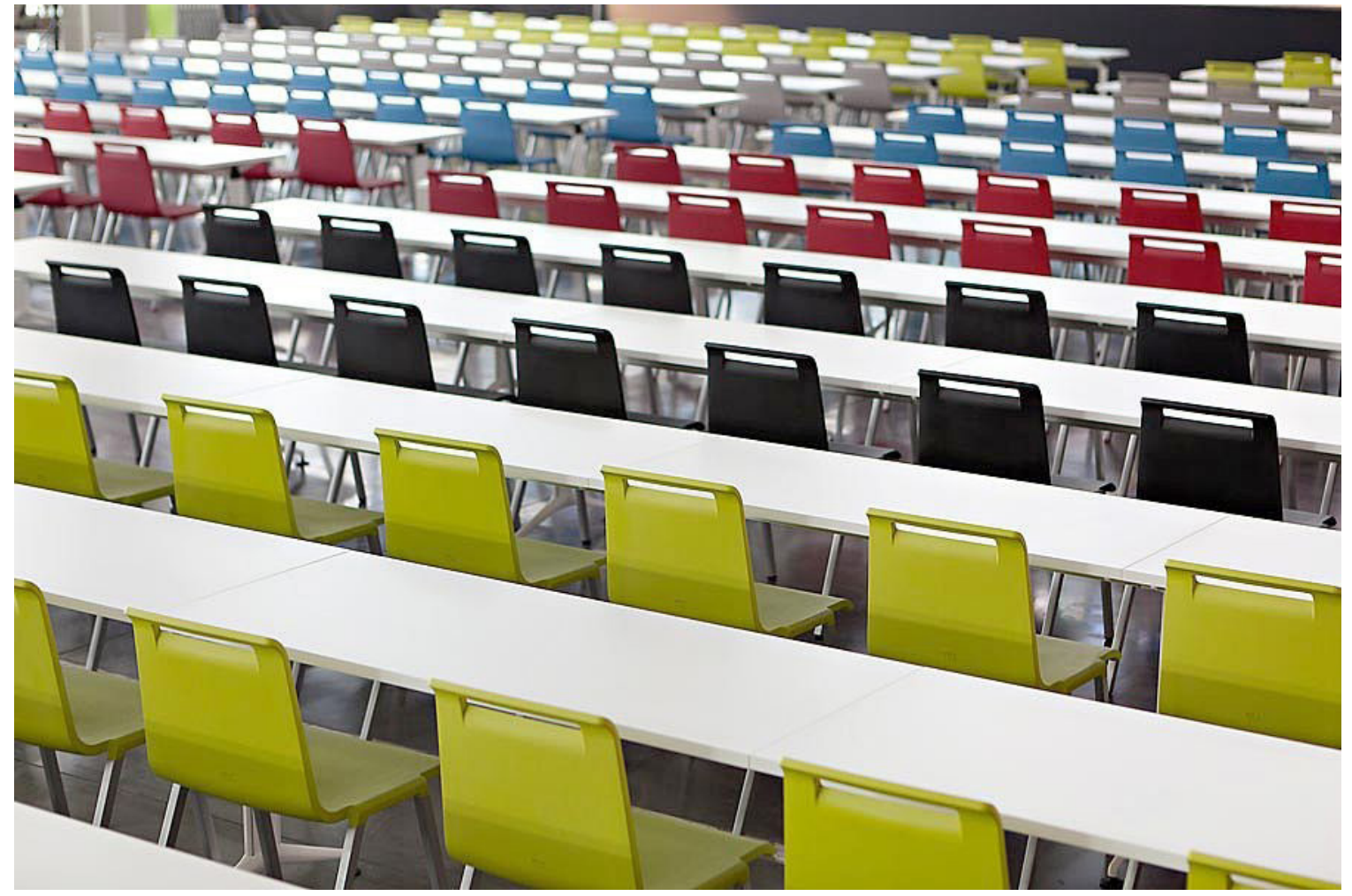

Fig. 6. www.actiu.com

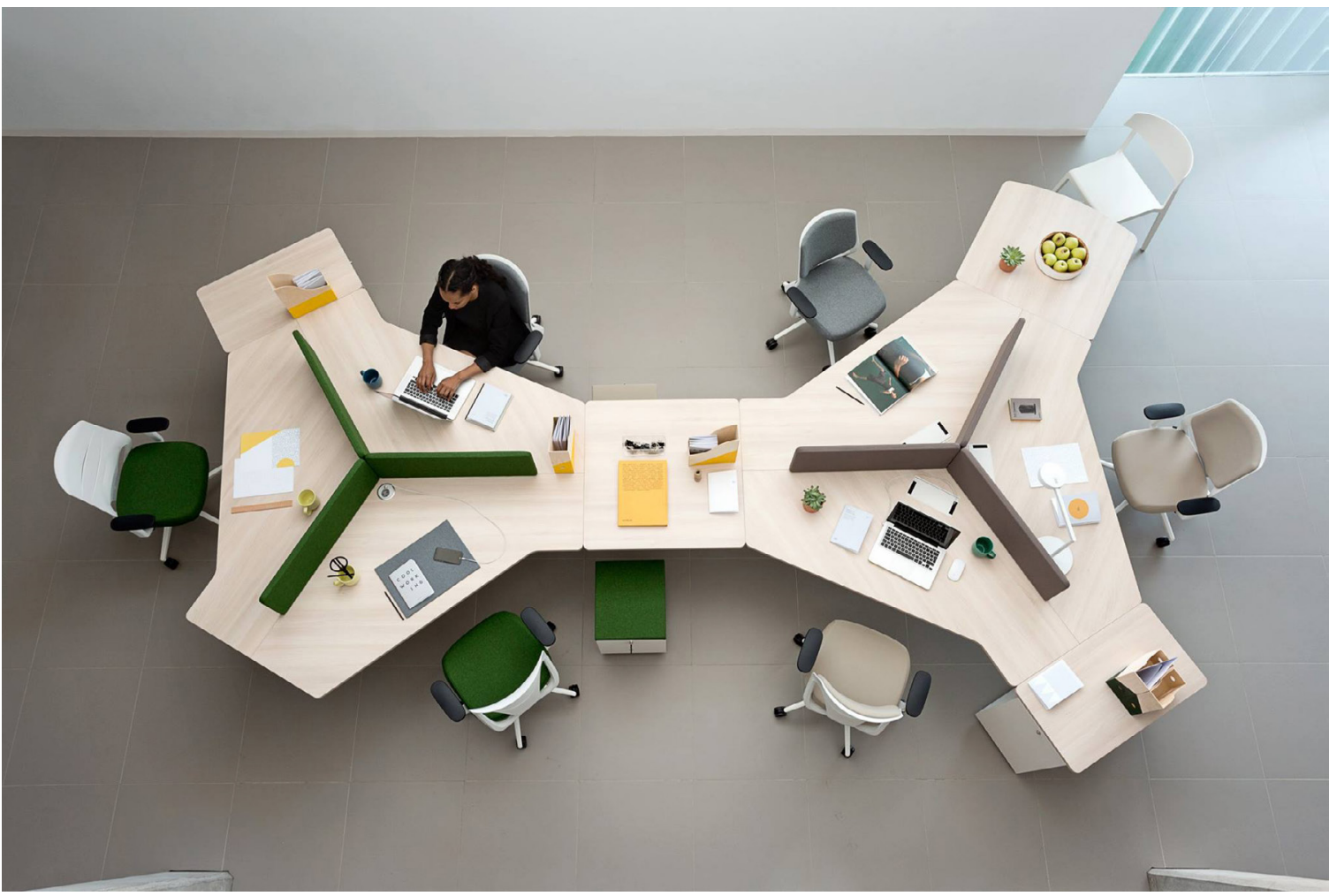

Fig. 7. Muebles de oficina. www.actiu.com 